\title{
Ten Years of the UK's Equality Standard for Sport
}

\author{
Adam Dwight ${ }^{1}$ and Kay Biscomb ${ }^{2}$ \\ ${ }^{1}$ City of Wolverhampton College, ${ }^{2}$ University of Wolverhampton, UK
}

\begin{abstract}
In 2004 the four UK Sports Councils introduced the Equality Standard for Sport. The purpose of The Standard was an approach of policy development through consultation and partnership with National Governing Bodies and built on the lessons learnt through the Racial Equality Standard for Sport (2000). Furthermore, The Standard aimed to recognise the multiple nature of inequality, beyond racial grounds and embrace a wider set of protected characteristics. Whilst this widening scope to The Standard is a positive move, its methodology and focus is still largely founded on an outcome based approach grounded in an audit culture. Previous research on The Standard was critical of this over reliance on the formalised audit approach, its failure to encourage organisations to be reflective on their history and culture and to promote organisational involvement in creating equality policies (Shaw, 2007). This paper provides a comparative analysis to the previous review of The Standard (Hudson \& Barlow, 2005; Shaw, 2007) and aims to examine what difference it is making in terms of equality, diversity and inclusion within sports organisations. Results indicate that there is proactive work carried out by sports organisations to widen the appeal of their sports with previously underrepresented groups but it is not clear how much of this work is from a direct result of The Standard. Furthermore, although many organisations had an aspiration to achieve Intermediate Level, very few have progressed beyond the Preliminary Level.
\end{abstract}

Keywords: inclusion; Equality Standard for Sport, inequality, equality, governing body

\section{Introduction}

Sport can play a major role in promoting the inclusion of all groups within society however, in reality significant inequalities have traditionally existed within sport in the United Kingdom (UK) and these inequalities stretch beyond participation into wider structural issues (Macmillan, 2016). The four UK Sports Councils introduced the Equality Standard for Sport in 2004, in an attempt to address the significant inequalities that existed in the sports industry. The Equality Standard (hereafter referred to as The Standard) was developed in the context of learning the lessons and successes from the Racial Equality Standard for Sport that was first introduced in 2000 by the organisation Sporting Equals which had been funded by the Commission for Racial Equality (CRE) and Sport England (Spracklen, et al., 2006). The Standard identifies some key definitions of terms such as equality is "the state of being equal treating individuals equally which is not necessarily treating people the same" (Sports Council Equality Group, 2014, 5) and with a view that diversity is concerned with respecting difference. Furthermore it provides a definition of inclusion as "Positive action taken to include all sectors of the community by reducing inequalities between disadvantaged groups and the rest of society, by closing the opportunity gap and ensuring that support reaches those who need it most” (Sports Council Equality Group, 2014, 7). 
The development of both the Racial Equality Standard for Sport and The Equality Standard for Sport was in the context of increasing government intervention and funding in the sporting arena in the UK. This incentive for funding arose following the 1997 election of the New Labour government who were keen to use sport to promote social inclusion and equity (Levitas, 1998; Lusted \& O’Gorman, 2010). Funding was largely channelled through Sport England and the other Sports Councils who followed New Labour's approach of setting specific evidence based targets to measure the value of this investment (Newman, 2001). The then Government policy and approaches adopted by the Sports Councils were therefore too often focused on hierarchical imposition of equality policies that were often reliant on simplistic quantitative outcomes (Shaw, 2007). This approach often had limited meaning for staff and members of the sports organisations (Acker, 2000; Shaw and Penney, 2003) and was in contrast to the recommendations that encouraged greater equity through proper leadership, engagement, reflection and self-critique (Meyerson \& Fletcher, 2000; Newman, 2002; Rao et al., 1999). One advantage of The Standard, however, was that in comparison to previous equality policies there was a removal of clear links to funding which had been seen as an imposition by some organisations (Shaw \& Penney, 2003).

Instead the approach of The Equality Standard seemed to be more of one of policy development through consultancy and partnership (Newman 2002) which still needs to be critically scrutinised since: "the focus on a more inclusive policy process raises a number of important issues about who is to be included, at what levels of decisionmaking, on whose terms, and with what forms of accountability” (Newman, 2002, 8). This is clearly a pertinent issue when analysing the impact of the consultation work required by The Standard, since the evidence suggests that NGB's Boards of Directors in the UK are largely unrepresentative of the wider population (Sporting Equals, 2012; Women's Sport and Fitness Foundation, 2014). Furthermore, it is not at all clear to what extent the consultation work is disseminated across the whole organisation and results in real change.

Despite these concerns The Standard was developed to recognise the multiple nature of inequalities that exist in sport beyond simply racial grounds and intended to embrace all those characteristics that are now protected by The Equality Act 2010 and to some extent Section 75 of the Northern Ireland Act $(1998)^{1}$. The Equality Act covers the following nine Protected Characteristics; age, disability, gender reassignment, marriage and civil partnership, pregnancy and maternity, race; religion or belief, sex and sexual orientation. The legislation does not just cover individuals who have these characteristics but also provides protection for someone who is perceived to have one of these characteristics or where they are associated with someone who has a protected characteristic. In working towards The Standard, sports organisations across the whole UK are expected to take these characteristics into account. This can be seen to be a positive move because the reality is that most sports operate in a male, cisgender, white, heterosexual, able bodied, middle-class

\footnotetext{
${ }^{1}$ The differences in the Northern Ireland Act (1998) lie in pregnancy, maternity, gender reassignment and political opinion.
} 
environment and these inequalities exist at all levels within sport including participants, coaches, officials, volunteers, administrators and employees (Spracklen et al., 2006; Long et al., 2005; King, 2005; Hylton \& Totten, 2001; Shaw and Frisby, 2006, Jones et al., 2016). Despite this positive move, the methodology and focus of The Standard is largely founded on an outcome based approach grounded in an audit culture that is extremely limiting since "audit culture and the bureaucratisation of equality is at odds with process-oriented research in this area and falls short of providing cultural and structural change within organisations" (Shaw, 2007, 230).

In 2005 Sport England and the Equality Standard Pilot Steering Group commissioned research to establish some baseline data from a survey issued to the Sports National Governing Bodies who were involved in the pilot stage of The Equality Standard (Hudson \& Barlow, 2005). At the time the intention was to issue the survey again in 2007 after the first NGB's had gained the Foundation levels of The Standard but this re-assessment never took place. Therefore ten years after the introduction of The Standard and with the introduction of The Equality Act (2010) this paper aims to examine 'what difference The Standard is making, in terms of Equality, Diversity and Inclusion within sports organisations'? It will also compare progress since the 2005 Survey was issued, examines whether organisational culture is a barrier for progress and explores solutions to overcome such barriers. This research is also significant because it addresses an empirical research gap by evaluating a major sport policy which has been embedded within Britain for the last ten years. Furthermore, in light of the development of equality legislation in the UK it is time to review this policy against the current levels and extent of the law.

One strand of sport research into areas of difference and inequalities has been described as "categorical" (Dowling, Fitzgerald and Flintoff, 2012) due to the tendency to allocate groups to single protected characteristic categories and then compare those categories. This characterises much of the research into equality issues in sport and that research tends to utilise the theoretical basis of the single strands e.g. feminist frameworks or critical race theory. Furthermore, Shaw (2007) challenges sport researchers in equality to adopt a broad perspective that will allow for different axes and appreciate their interrelationships. Therefore, in order to address this difficulty we will adopt the same theoretical framework used by Shaw (2007) in her analysis of The Standard. This framework is a broad perspective which proposes an analysis of structural constraints, allowing for the acknowledgement of multiplicity of protected characteristics and an understanding that there may a tessellation between one or more characteristic (Shaw, 2007). Three strands of this organisational approach are: "encouraging organisational involvement; critiquing taken-for-granted assumptions and addressing organisations' "deep structure” (Shaw, 2007, 421). The results are discussed in the context of three strands theoretical framework and goes some way to addressing Shaw's call for further research in this area.

\section{Method}

A questionnaire was designed to mirror the work previously conducted with some amendments (Hudson \& Barlow, 2005). The original survey was updated to include other relevant protected characteristics identified in the Equality Act (2010). It consisted of 38 questions, 34 of which utilised a Likert scale, prompting numerical 
responses ranging from 1-4 with ratings of 'Not at all' for a score of 1 and 'Greatly' for a score of 4 . Like the first survey an option to choose 'Data not available' was provided where appropriate. Seventeen questions focused on to what extent, the organisations represent individuals from various protected characteristics in terms of their membership, National Council / Board and staff. Six questions focused on the commitment to, knowledge base and perceived benefits of the Standard. Three questions allowed respondents to provided unstructured and qualitative responses and these questions focused on the challenges that organisations faced in achieving The Standard, assistance required and benefits in obtaining The Standard. Ethical approval was gained from the relevant University ethics committee.

The names of the organisations to contact were obtained from the directory of achievements section on The Standard website (Sports Council Equality Group, 2015) with the initial intention of contacting all of the target population that had obtained various levels of The Standard (229 organisations). Sport Wales acted as a gatekeeper to distribution and provided a list of key contacts for a number of sports organisations in Wales. For the non-Welsh organisations publicly held contact details were used to distribute the survey. As a result, from the target population of 229 organisations that had achieved The Standard, 74\% were contacted (all those where emails had been available) with a 170 emails distributed with an explanation of the context of the research and the web based survey. A web survey was used, using the Survey Monkey website, since previous research has shown to be an effective means of distribution (Walters et al., 2010). This was sent through email where possible to the Equality Lead or the Chief Executive or Chairpersons of these organisations.

The response rate was $25 \%(n=42)$ which contrasts with the previous response rate of $100 \%$ (English NGBs) and 35\% (UK NGBs) and there were some clear reasons for these differences. The 2005 research was endorsed by Sport England and the Equality Standard Pilot Project Steering Group who nominated many of the organisations who were sampled as part of the Pilot implementation of The Standard. The researchers in the 2005 project also secured a high response rate by telephoning the organisations in advance to provide a brief on the research and to agree a time and date for the survey to be conducted, again via a telephone conversation. A similar approach was not possible in this survey because there was not the same level of support and endorsement from the Sports Councils. Despite the lower response rate, the 42 respondents in the 2015 survey included a wide variety of organisations with 29 NGB's, six County Sport Partnership and seven other organisations from across the home countries and the United Kingdom. For the questions that provided qualitative responses, NVIVO software was used to breakdown the sources of the respondents in terms of job title and type of organisations and the software supported a thematic analysis in terms of responses to questions. The themes that emerged from this thematic analysis in relation to challenges to gaining the Equality Standard included encouraging organisational involvement, taken for granted assumptions and deep structure.

\section{Results and Discussion}

The initial section focuses on the quantitative responses to the survey offering a comparative analysis with the results from the 2005 survey (Hudson \& Barlow, 2005) 
which had formed two separate reports; one report for Sport England including the 24 English NGB's surveyed and the other report for the Equality Standard Pilot Project Steering Group including the 38 UK NGB's surveyed. In the first few sections, this will focus on the responses in terms of how organisations represent individuals from various protected characteristics in terms of their membership, National Council / Board and staff. The qualitative results conclude the section.

Quantitative results

\section{GENDER}

When comparing both past and current results gender is still the protected characteristic that is most effectively represented within the NGB's and sports organisations. However, the survey results seem to indicate that significant progress has not been made in the last 10 years in terms of the representation of females within NGB's and sports organisations. The survey documents representation for membership, board level and staff and Table 1 outlines all of these strands. Results indicate that there has been a slight drop in female members when compared to England but a slight increase when compared to all of the UK. This differential in pattern is repeated for board level representation and staffing but previous results in this area demonstrate that England's representation was much lower than that for the UK.

Despite the growth in participation by women in sport, the slow progress of the representation of females within the governance of sport has been an underlying theme in much of the academic research over the last thirty years (Hall et al. 1989; Cohen, 1993; Hargreaves, 1994; Birrell \& Theberge, 1994; Shaw \& Slack, 2002; Ferris, 2000). With the increased intervention of the state, professionalisation and bureaucratisation of sport in the 1980's, there was a hope this would provide new opportunities for women as 'new professionals' but the ground breaking research of White and Brackenridge (1985) found the opposite to be true with an even greater gender dominance by men in 1980's compared to the 1960's and 70's. Their research found that women still have very little power and influence in British sports organisations with very small numbers of female officials, executives of voluntary governing bodies, and professional administrators and coaches (White \& Brackenridge, 1985).

Table 1- Representation by Females

\begin{tabular}{|llrr|}
\hline a) Membership & & & \\
\hline & & Not at all & Greatly \\
& 2005 UK NGB's (\%) & 3.0 & 30.0 \\
& 2005 English NGB's (\%) & 14.0 & 38.0 \\
& 2015 Survey (\%) & 0.0 & 34.3 \\
b) National Council / Board & & & 35.0 \\
\hline & 2005 UK NGB's (\%) & 29.0 & 19.0 \\
& 2005 English NGB's (\%) & 5.6 & 33.3
\end{tabular}




\section{UK NGB's (\%)}

2005 English NGB's (\%)

2015 Survey (\%)

This lack of progress is also emphasised further by research carried out on an Annual basis between 2009-2014 by the Women's Sport and Fitness Foundation (WSFF) in partnership with our Commission on the Future of Women's Sport. The reports, entitled Trophy Women (WSFF 2014), have consistently showed alarmingly low levels of female representation across national governing body (NGB) Boards and senior management teams and in 2013, of the 57 NGB's surveyed, 31 NGB's failed to meet UK Sport and Sport England's minimum expectation that their Boards should comprise at least $25 \%$ women. In 2009, women made up only $21 \%$ of the Board Members within NGBs and this had only risen to 22\% in the 2013 (WSFF 2014).

The WSFF (2014) research outlines some clear reasons for the underrepresentation of women that include institutionalised structures and recruitment processes in which boards that are comprised of male dominated volunteers with unlimited tenures and new members are drawn from similarly male dominated staff and members. It also describes an inhospitable culture that is based on a machismo discourse that includes stereotyping and discrimination and / or an unwillingness to provide facilities to accommodate women.

These findings simply confirm previous research that has found the importance of taken for granted assumptions and discourses that influence employment roles and the way women's and men's roles are understood within sport organisations (Shaw \& Hoeber, 2003). Discourses of masculinity, often linked to leadership roles and men, are influential within organisations and often serve to undermine discourses of femininity that are frequently associated with subordinate roles and women (Kerfoot \& Knights, 1998). Again we are returning to the recurring theme of the influence and importance of organisational culture and in this case how the discourses of masculinity and femininity help us to understand how assumptions about men and women in various employment roles are formed and why they have such longevity and influence, often allowing men to have greater access to senior employment roles than women. Until these organisational cultures and discourses in sports NGB's are further explored and analysed it is unlikely that strategies to increase the proportion of women on Boards at NGB's will be successful.

In 2006, there was an attempt to update White and Brackenridge's (1985) original research and the findings were more encouraging with female involvement in governance growing (White \& Kay, 2006) although interestingly, they established a clear link between the numbers of women in power and age of the organisation:

Where the organization is under 10 years old, there is a greater likelihood of equal representation of men and women in positions of leadership and influence. By way of illustration, Sports Coach UK, UK Athletics and UK Sport, as they are now, have all been established within the last 10 years and have a minimum of 50 percent of their staff, councils and committees made up of women. (White \& 
Kay, 2006, 470)

This serves to re-emphasise the importance of an established organisational culture and the barriers that it can create with efforts for sports organisations to become more inclusive and representative. This is not to say that older more established organisations cannot seek to change their culture and recognise the input of females and other groups, since White and Kay (2006) note that the Central Council for Physical Representation (CCPR), that was founded in 1935, has a staff population who are $80 \%$ female and 55 percent of its Board members are women. They attributed this to the fact that the CCPR 'reinvented' itself in 1995 after a restructure of staffing due to financial irregularities.

\section{DISABILITY}

Although there are much lower levels representation by disabled people in the NGB's / Sports organisations surveyed, there has been some marginal improvement. There is a slight increase in the membership figures and better representation at board level but this should be contrasted to the slight decline in staffing representation.

Table 2: Representation by disabled people

\begin{tabular}{|llrr|}
\hline Membership & & & \\
\hline & 2005 UK NGB's (\%) & Not at all & Greatly \\
& 2005 English NGB's (\%) & 16.0 & 11.0 \\
National Council / Board & 2015 Survey (\%) & 19.0 & 10.0 \\
\hline & 2005 UK NGB's (\%) & & 14.7 \\
& 2005 English NGB's (\%) & 70.0 & 5.0 \\
Staff & 2015 Survey (\%) & 62.0 & 0.0 \\
\hline & & 30.6 & \\
& 2005 UK NGB's (\%) & 54.0 & 3.0 \\
& 2005 English NGB's (\%) & 52.0 & 5.0 \\
& 2015 Survey (\%) & 19.4 & 2.8 \\
\hline
\end{tabular}

So progress has been made, but it has been slow, and in many ways this is reflective of the more general development of disability sport in the UK that has largely been dependant on the contribution of disability sports organisations such as the British Sports Association for the Disabled (BASD), British Paralympic Association (BPA) and more recently the English Federation of Disability Sport (EDFS) (Thomas \& Smith 2009). Ironically the EDFS was originally established in 1998 from a political agenda, led by the Government and the Sports Council, to shift responsibility for the coordination and delivery of disability sport to mainstream National Governing Bodies (Collins, 1997) but these objectives were never achieved with the President of EDFS commenting that these NGB's: "will never take on disability fully so we will need disability sports organisations well into the foreseeable future and quite possibly always" (Thomas \& Smith, 2009, 121). This merely reflects the dominant culture within sport and views disability from a medical, individualised approach (Thomas \& 
Smith, 2009) whereby sport provides 'therapy' for disabled people to aspire to the able bodied, physicality and athleticism of modern sport.

Some writers do challenge this concept in a critical manner since they argue that disabled people's participation in sport becomes an attempt to emulate non-disabled values and is merely an example of disabled people's struggle for acceptance in a predominantly able-bodied world (Hahn, 1984). In this sense disability sport is less about the true promotion of disability but instead merely an imitation of non-disabled sport in which disabled people are encouraged to accept a set of non-disabled values (Barton, 1993).

\section{RACE AND ETHNICITY}

Although there has been some limited progression in terms of representation of females and disabled people within the sports organisations unfortunately such progression is not matched in terms of Race and Ethnicity that has shown little improvement compared to the survey results from 2005.

In 2005, the survey identified low level of membership representation amongst Black and Minority Ethnic (BME) groups and there has been no significant change in patterns here with only $9 \%$ of the respondents stating that BME individuals were greatly represented within their memberships. Similarly there has been no positive change in the recent survey, with board level representation and in terms of staffing, there seems to have been a worsening position.

Table 3: Representation by Black and Minority Ethnic Group

\begin{tabular}{|llrr|}
\hline Membership & & Not at all & Greatly \\
& & 22.0 & 8.0 \\
& 2005 UK NGB's (\%) & 10.0 & 10.0 \\
& 2005 English NGB's (\%) & 5.7 & 8.6 \\
\hline National Council / Board & 2015 Survey (\%) & 68.0 & 5.0 \\
\hline & 2005 UK NGB's (\%) & 57.0 & 10.0 \\
& 2005 English NGB's (\%) & 50.0 & 11.1 \\
Staff & 2015 Survey (\%) & & 8.0 \\
\hline & 2005 UK NGB's (\%) & 39.0 & 19.0 \\
& 2005 English NGB's (\%) & 33.0 & 2.8 \\
\hline
\end{tabular}

These results simply mirror research that show disappointing progress in relation to the representation of people from a BME background with a report by Sporting Equals (2014) revealing that only 3\% of senior roles in Sports NGB's were held by those from a black or ethnic minority (BME) background and of the 45 NGB's surveyed, 30 NGB's or two thirds of the total had had no senior BME representation (Sporting Equals 2014). In many respects the lack of progress with representation by people from a BME background is linked to the failures of Sport Equity Policies in general in the UK since they fail to challenge embedded and normalised white hegemony outlined by critical race theorists (Hylton, 2005). Again we are referring here to the 
organisational culture that is so normalised that it is virtually invisible (Long \& Hylton, 2002) to those within these structures of governance and the qualitative results demonstrate that it is clear that a number of respondents were aware of the importance of challenging their existing organisational culture and attitudes and perceptions within their organisations.

\section{RELIGION, FAITH AND SEXUAL ORIENTATION}

Data on religion and faith and sexuality were not collected in the previous survey as these became protected characteristics in the Equality Act 2010. Consequently, a much larger proportion of organisations did not have data available to measure representation from these equality strands. This contrasting position was most pronounced with regard to the representation within the National Council / Board (see Table 4). As can be seen in all the data in Table 4, the organisations surveyed were far more effective at collecting data for the other protected characteristics.

Table 4: Data not available for different protected characteristics

\begin{tabular}{|c|c|c|c|c|c|}
\hline \multicolumn{6}{|l|}{ Membership } \\
\hline & Disability & Females & $\mathrm{BME}$ & Religion and Faith & LGBT \\
\hline 2005 UK NGB's (\%) & 27.0 & 10.0 & 19.0 & N/A & N/A \\
\hline 2005 English NGB's (\%) & 28.0 & 15.0 & 27.0 & N/A & N/A \\
\hline 2015 Survey (\%) & 20.6 & 11.4 & 20.0 & 31.4 & 40 \\
\hline \multicolumn{6}{|l|}{ Board } \\
\hline & Disability & Females & $\mathrm{BME}$ & Religion and Faith & LGBT \\
\hline 2005 UK NGB's (\%) & 3.0 & 3.0 & 5.0 & N/A & N/A \\
\hline 2005 English NGB's (\%) & 9.0 & 0.0 & 9.0 & N/A & N/A \\
\hline 2015 Survey (\%) & 5.6 & 0.0 & 0.0 & 25.0 & 36.1 \\
\hline \multicolumn{6}{|l|}{ Staff } \\
\hline & Disability & Females & $\mathrm{BME}$ & Religion and Faith & LGBT \\
\hline 2005 UK NGB's (\%) & 11.0 & 8.0 & 13.0 & N/A & N/A \\
\hline 2005 English NGB's (\%) & 14.0 & 0.0 & 0.0 & N/A & N/A \\
\hline 2015 Survey (\%) & 2.8 & 0.0 & 0.0 & 17.1 & 27.8 \\
\hline
\end{tabular}

Similar results could be found for the representation of different protected characteristics within the staff of the organisations surveyed but in terms of the membership, organisations were far less efficient in collecting data across all the protected characteristics although again the organisations were least effective in collecting in relation to different religious and faith groups.

There is not a universal consensus on whether organisations should be auditing all employees and volunteers on their demographic profile and some are critical of fact that The Standard encourages such data collection particularly in 'conservative' sports organisations (Shaw, 2007) since it's seen as intrusive (Spittal, 2002) and therefore discourages such staff from supporting and committing to equality programmes and policies. Some extend these concerns to include the prospect that the collection of this data could also identify members of minority groups within organisations and subject 
them to subtle, informal and exclusionary practices (Aitchison, 2000). However, without the collection of key data that measures the diversity of sports organisations, their staff, members and sporting participants, it will be difficult to gauge the progress being made with the inclusivity of these organisations. In fact, there is a widely held view that the collection of equality data plays a significant role in the equality agenda and that:

Poor measurement and a lack of transparency have contributed to society and governments being unable to tackle persistent inequalities and their causes. The data available on inequality are utterly inadequate in many ways, limiting people's ability to understand problems and their causes, set priorities and track progress (Equalities Commission, 2007,10)

Interestingly the same report also highlighted in particular the severe lack of data relating to sexual orientation and how this linked initially to the reluctance of organisations to either collect this data but also to the prevalence of the non-response to questions linked to sexual orientation (Aspinall \& Mitton, 2008) or a 'prefer not to say' response is given. More recent research has shown similar patterns in terms of responses linked to gender identity or the gender re-assignment protected characteristic. While some may argue that these responses are a reflection of the intrusive nature of this equality monitoring, it is clearly also a reflection of attitudes towards sexual orientation and gender identity within organisations and particularly how safe Lesbian, Gay, Bisexual, Transgender (LGBT) individuals are with disclosing their sexual orientation and / or gender identity. This is reflected in very recent research in post compulsory education (Further Education and Higher Education) that found:

LGB+ learners were almost 10 times more likely (37 per cent) to say that something would stop them declaring their sexual orientation than heterosexual respondents (4 per cent). Non-binary learners felt less confident about doing this than those who described themselves as male or female. (The Forum for Sexual Orientation and Gender Identity Equality in Post-School Education, 2016, 10)

\section{Qualitative analysis}

Emergent themes from the qualitative data mirror those identified by Shaw (2007) of encouraging organisational involvement, taken for granted assumptions and deep structure, and these are now be explored in turn.

\section{ENCOURAGING ORGANISATIONAL INVOLVEMENT}

In analysing the qualitative data, it is important to note that there is some variance in responses according to the position held within the sports organisation by the respondent. For instance, in the responses to the question about major challenges that the organisations face in working towards the Standard, when the Head of the organisation (Chief Executive or Chairperson) completed the survey, the responses were generally brief, straightforward and were most commonly linked to a shortage of 
time and / or other resources. In contrast, when the survey was completed by another Senior Manager or particularly staff with responsibility for Equality and Diversity within the sports organisations, the responses were more detailed, self-critical of the role of the organisation itself and far more likely to identify complex factors linked to attitudes, traditions and organisational cultures within the organisation.

Locating equality and diversity on the periphery of the organisation, and therefore not encouraging holistic organisational involvement, was noted in a number of ways. This included a recognition that the strategy existed and a belief that not adopting an embedded approach was least likely to result in success. Responses that were more self- critical of the organisations, commonly received from staff who are not Chief Executive Officer's (CEO) or Heads of the organisation, refer to the need for Equality to be embedded throughout the organisation with clear strong leadership to facilitate this such as "Commitment from the Board to take action to address issues. Ensuring that equality permeates all our work and that the impact and implications for all groups are considered and addressed." (Senior Manager, Sports Organisation). This contrasts with Shaw's (2007) view that the danger of this approach is that is creates a hierarchical approach to policy development and potentially limits the opportunities for individuals to contribute.

This perspective within organisations classifies equality and diversity activities as the responsibility for just certain 'other' individuals within organisations rather than at the centre of the strategic decision making process. This approach is limiting since: "As long as diversity remains 'the other' it was doomed. The decision-making powers and associated resources would never be focused on it. So diversity had to be brought back into the realm of the current and present' (Frost, 2014 105). This perspective, which was a common response from the Heads of the Sports organisations, is too some extent based on a false premise that the Equality and Diversity activities needed to gain the Standard form a separate agenda or area of work that is: "a burdensome initiative to bear, rather than something that could add value” (Frost, 2014, 41).

Frost (2014) writes from the perspective as the first ever Head of Diversity and Inclusion for an Olympic Games working for The London Organising Committee of the Olympic and Paralympic Games (LOCOG) in the run up to the 2012 event. LOCOG became the only organisation to gain the Advanced level of the Equality Standard for Sport and gained this achievement within 2 years, bearing in mind that no other organisation has still achieved the Advanced level in over a decade and few other Sports organisations have either gone beyond the Preliminary level of the Standard.

LOCOG were so successful since equality was embedded throughout their work, rather than seen as a separate agenda, and Frost (2014) reveals that as a private sector organisation this approach was based on a real business case for inclusion work that would include customer relevance, employee attraction, removing barriers to growth, better decision making and ethics. This approach is the antithesis of a zero sum approach in which organisational effectiveness is thought to be adversely affected by the implementation of equity policies and practices and instead these policies should be seen as essential for the effective functioning of the organisation (Shaw and Frisby, 2006; Frisby 2005). 


\section{TAKEN FOR GRANTED ASSUMPTIONS}

Shaw (2007) criticises The Standard's approach because it does not provide a mechanism by which individuals might review barriers by minority groups and that challenging taken for granted assumptions is undertaken through structural analysis rather than individual reflection. One respondent stated that "Culture and tradition are two things that currently stand in the way" (Equality Officer, NGB) while a number of other responses focused on the importance of raising awareness for all staff across the organisation:

"Staff having understanding of the various strands that the organisation requires to demonstrate to achieve the standard. There needs to be a cultural shift and this is the major challenge that all NGBs would face.” (Equality Officer, NGB)

Some respondents made clear reference to internal barriers within their own organisation including a response from a large sports organisation that stated that the Standard was "challenging to existing policies and procedure" (Senior Manager, Sports organisation) and one could anticipate that a reluctance to simply adapt these policies and procedures is again linked to deep seated negative attitudes and organisational culture.

This referral to the importance of cultural and structural changes within organisations, if real progression is going to be made is reflective of previous research on the Standard that expressed doubts that the Standard will facilitate such development (Shaw, 2007; Spracklen et al., 2006). Some respondents recognised that changing perceptions and awareness may be insufficient for cultural change and that more active engagement of staff was required with one respondent stating:

"Ensuring that all staff/members are engaged in the process. We currently hold the intermediate standard and will be working towards the advanced standard in the near future but need to ensure that awareness of equality challenges is embedded across the organisation.” (Equality Officer, NGB)

The self-perpetuating make up of sports organisations, in terms of their middle class, white, male, heterosexual make up, seems to be linked to cultural and institutional barriers that the Standard itself may struggle to overcome. This is not to imply that organisations are governed by leaders who deliberately obstruct change and progression but simply that much of the effort to promote equality is hampered by a lack of understanding in sport of the dominance of the prominent organisational cultures such as Whiteness (Long \& Hylton, 2002), Heteronormativity (Caudwell, 2011), gendered discources (Alvesson \& Billing, 1997; McKay, Messner, \& Sabo, 2000; McNay, 2000; Woodhouse \& Williams, 1999) and able bodied physicality (DePauw \& Gavron 1995) that help to reinforce the current demographic composition.

As previously mentioned, some respondents to the question about major challenges that the organisations face in working towards the Standard and to the question, that asks organisations what assistance they need in order to address these challenges, make clear reference to limited time and resources as a barrier particularly with competing priorities and budget restrictions. This is reflective of these views in 
stating about challenges, "Time and staff resource - balancing the demands of all other priorities with a depreciating budget position” (CEO, NGB).

Other respondents recognised that The Standard has initiated a response that encouraged their organisations to adopt a more critical approach when reflecting on their own governance, processes and practices. For example one organisation referred to how the Standard provided a framework and structure for "Ensuring systems, training and processes are in place to be equitable in planning, approach and performance" (CEO, County Sports Partnership). While this is facilitating action rather than change, it is nevertheless encouraging that organisations are looking inward at their own organisations and processes that are barriers to equity. This critical approach will be essential to change although Thompson \& Thompson (2008) emphasise the importance of what they call 'critical depth' and 'critical breadth'. Critical depth links effectively to the previous points made about the importance of organisational culture since it emphasises the need for organisations to look beyond the surface at taken for granted assumptions and discourses that exist. Without critical depth, there is a danger that reflective practice will be shallow and be unlikely to take into account the complexity of the factors that exclude and prevent progress (Thompson \& Thompson 2008).

While reflective practice within the organisation can be the most powerful tool in implementing change, external support and The Standard itself may have a role to play in encouraging organisations to move towards this approach. To some extent this may be linked to the methodology for assessment for The Standard and one organisation made specific reference to the assessment methods being adopted by Sports Wales that are both rigorous and also supportive: "In Wales we do a presentation to a panel which is incredibly useful, and it allows us to pose questions to the panel who can then take that back and make suggestions accordingly" (Manager, Sports organisation). The researcher's own observations of this form of assessment, by the Sports Wales Equality Standard Assessment Panel, in the summer of 2014, can confirm the rigour of the process although the focus was very much on the programmes and initiatives being implemented by Sports NGB's and their work with their participants and membership rather than the sports organisations' own internal structures, processes and organisational culture.

\section{DEEP STRUCTURE}

The concept of empowerment and engagement could be a powerful tool in embedding equality while at the same time having a more significant impact on the 'deep structure' (Rao et al., 1999) of organisational cultures by challenging formal and informal existing policies and practices. The key question however is whether the Standard is the appropriate tool to facilitate such engagement and challenges to organisational practices and cultures when the lower levels of the Standard focus predominately on process orientated objectives linked to Policies and Plans rather than actual practices (Spracklen et al., 2006).

Nevertheless, there is a clear link in many of the responses between knowledge and engagement although the forms that this engagement should take do vary in kind, including staff being encouraged to report discriminatory practice. For instance, the following response, is fairly typical: "Understanding the perceived barriers presented 
to underrepresented groups. Instilling confidence in all to report any acts of inequality.” (Equality Officer, NGB).

These responses acknowledge the view that leadership within sports organisations have a significant role in the creation and reinforcement of organisational culture within these organisations although at times this can be as powerful in maintaining the status quo as influencing change. Previous research has found that leaders of sports organisations will contribute to the communication of taken for granted assumptions Dyer (1997) and norms that imply that sports and sports governance is naturally a meritocracy and thus: "people responsible for running sport cling to the belief that sport is culture blind," (Long et al, 2005, 52)

The success of LOCOG was reliant on adopting an approach previously identified by Ely and Thomas (2001) in which drawing on a more diverse audience of staff and customers is not about just gaining access to a niche market but rather, their attitudes, ideas, and creativity should be valued equally throughout the organization to broaden perspectives, to develop new strategies and networks, and to foster innovation. NGB's and Sports organisations can learn the lessons from LOCOG in appreciating that institutional culture has an impact on embedding inclusion and Diversity as long as the deep structure is analysed (Shaw, 2007). As such there needs to be a clear strategy that emphasises empowerment, personal responsibility and leadership within organisations.

Some responses indicated a desire to use external expertise to advise the organisation on their policy and progress. This seems a different approach to the empowering culture at LOCOG and links to previous research on The Standard that found that by itself The Standard is insufficient and should be part of a wider equality and diversity management framework that changes attitudes and ways of working and works bottom-up as well as top down (Spracklen et al. 2006). The weaknesses of this imposed compliant style seems to be as relevant to the philosophy that underpins the Standard as to a Management style that believes that inclusivity can be forced about (upon) members of an organisation. This approach is also reflected in other responses to the question about the benefits of gaining The Standard with one stating: "It is pretty much for us an exercise for funding. It can be used as a kite mark, this is not the view we get from other partners” (CEO NGB).

\section{Conclusion}

Another focus of Shaw's (2007) analysis was the danger that audit approaches results in focussing on outcomes at the expense of equality processes. This is mirrored in these findings particularly the recognition that there is little progress towards the next level of The Standard. Shaw's further criticisms of The Standard suggest that using this methodology leads to a difficulty in organisational involvement, does not fully engage with addressing taken for granted assumptions and does not encourage organisations to have an understanding of their institutional deep structure are still prevalent in these findings. Although Shaw's initial research was a textual analysis of The Standard itself, the empirical data gathered from these organisations support Shaw's theoretical framework from an experiential perspective. Clearly a commitment from the Chief Executive and / or Equality Lead should be expected however in order for equality policies to be successful, organisational involvement is required from all members (Bagilhole, 2006) otherwise policies can quickly become tokenistic or 
piecemeal. Despite this desire and commitment, the survey identified that barriers still exist for these organisations fulfilling these aspirations including understanding of the relevant issues and the right level of knowledge to ensure their organisation operates equitable.

Nevertheless, this research reflects the fact that there is some excellent work being carried out by Sports NGB's, County Sports Partnerships and other sports organisations, to widen the appeal of their sports with previously underrepresented groups. It is not clear from this research about how much of this work is a direct result of The Standard but many respondents did concur that The Standard has had a positive impact in encouraging some of this work even if this largely takes the form of Sports Development initiatives to widen participation. However, despite the fact that nearly half of the respondents, to this research, expressed aspirations to progress past the Preliminary Level of The Standard by March 2016, the fact that so few organisations have reached the Intermediate Level does suggest that little has changed from when research was carried out on the Racial Equality Standard for Sport (Long et al., 2005) and concluded that:

Evidence to date suggests that many sports organizations are content to do what is required of them to reach the preliminary level (make a public commitment, adopt a policy, and undertake monitoring) but show little enthusiasm for doing more than they are obliged to do. (Long et al., 2005, 53)

Although there was evidence in this research that The Standard encouraged some organisations to take a more critical look at themselves, it is interesting that this was not a common view in the feedback received from CEO's who responded to the research. Instead these respondents often sought solutions and support from sources that were external to their organisations rather than taking ownership of the issues and demonstrating leadership. To some extent this is reinforced by the consultancy approach (Newman 2002) adopted in the implementation of The Standard particularly if this work is not disseminated across the whole organisation.

The criticisms of the Standard in academic literature remains valid since the Standard is still outcome based rather than encouraging a more critically reflexive approach that focuses on processes within organisations (Shaw, 2007) and ultimately accredits evidence of action rather than change (Spracklen, 2006). This research reinforces the need for change since the evidence collected suggests that progress is still slow in terms of wider representation of underrepresented groups in the staff, membership and particularly National Councils and Boards. This paper has emphasised the need for structural and cultural changes within organisations and for a Standard that will encourage the leaders of these organisations to be more critically reflexive and to empower and engage with their own staff and members to implement change.

\section{Notes on contributors}

Adam Dwight is a Teaching and Learning Coach from the City of Wolverhampton College, Wolverhampton, England. His main interests lie in all areas of equality and diversity especially relating to the sports setting. 
Kay Biscomb (Corresponding Author) is an Associate Dean in the Faculty of Education, Health and Wellbeing at the University of Wolverhampton. Her main research interests are in equality, media representation and identity. (contact: Walsall Campus, Gorway Road, Walsall, WS1 3BD. K.Biscomb@wlv.ac.uk)

\section{References}

Acker, J. (2000). Gendered Contradictions in Organizational Equity Projects. Organization [online], 7(4), 625-632 Available at: http://org.sagepub.com/content/7/4/625.short.

Aitchison, C. (2000). Poststructural feminist theories of representing others: a response to the ‘crisis’ in leisure studies’ discourse Leisure Studies, Vol. 19(No. 3), 127-144.

Alvesson, M. and Billing, Y.D. (1997). Understanding gender and organizations. London: SAGE Publications.

Aspinall, P.J. and Mitton, L. (2008). Operationalising 'sexual orientation' in routine data collection and equality monitoring in the UK. Culture, Health \& Sexuality, 10(1), 5772.

Bagilhole, B. (2006). Family-friendly policies and equal opportunities: a contradiction in terms? British Journal of Guidance \& Counselling, 34(3), 327-343.

Barton, L. (1993). Disability, empowerment and physical education. In Evans,J.(ed). Equality, Education and Physical Education. London: The Falmer Press, 43-54.

Birrell, S. and Theberge, N (1994). Ideological Control of Women in Sport. In Costa, D. M. and Guthrie, S. R.(eds). Women and sport: Interdisciplinary perspectives. Champaign, IL: Human Kinetics.

Caudwell, J. (2011). 'Does your boyfriend know you're here?' The spatiality of homophobia in men's football culture in the UK. Leisure Studies, 30(2), 123-138.

Cohen, G.L. (1993). Women in sport: issues and controversies. London: Sage Publications.

Collins,D. (1997). Conference Report. National Disability Sports Conference. London, Kings Fund Centre.

DePauw, K.P. and Gavron, S.J. (1995). Disability and sport. Champaign, Ill: Human Kinetics.

Dowling, F., Flintoff, A. and Fitzgerald, H. (2012 (eds.). Equity and difference in physical education, youth sport and Health: A Narrative Approach. London: Routledge

Dyer, R. (1997). White: Essays on Race and Culture. New York: Routledge.

Ely, R.J. and Thomas, D.A. (2001). Cultural Diversity at Work: The Effects of Diversity Perspectives on Work Group Processes and Outcomes. Administrative Science Quarterly [online], 46(2), 229-273 Available at: http://asq.sagepub.com/content/46/2/229.abstract.

Equalities Commission (2007). Fairness and freedom: the final report of the Equalities Review. London, Equalities Review. 
Frisby, W. (2005). The Good, the Bad, and the Ugly: Critical Sport Management Research Journal of Sport Management. [online], 9(1), 1-12. [Accessed 7/12/2015].

Frost, S. (2014). The Inclusion Imperative: How Real Inclusion Creates Better Business and Builds Better Societies: Stephen Frost: 9780749471293: Amazon.com: Books [online]. [Accessed 11/9/2015]. Available at: http://www.amazon.com/The-InclusionImperative-Business-Societies/dp/0749471298.

Hahn, H. (1984). Sports and the political movement of disabled persons: examining nondisabled social values. Arena Review, USA, 8(1), 1-15.

Hall, M. A., Cullen, D. and Slack, T. (1989). Organizational Elites Recreating Themselves: The Gender Structure of National Sport Organizations. Quest [online], 41(1), 28-45 Available at: http://dx.doi.org/10.1080/00336297.1989.10483906.

Hudson, C. and Barlow, M. (2005). English National Governing Bodies Self Assessment Survey Sport England. [Accessed 3/20/2015]. Available at: www.vagaassociates.com/Documents/SHU\%20English\%20NGBs\%20Report.ppt.

Hudson, C. and Barlow, M. (2005). UK National Governing Bodies Self Assessment Survey Equality Standard Pilot Steering Group. [Accessed 03/20/2015]. Available at: www.vagaassociates.com/.../UK\%20NGBs\%20Report\%20(2)\%20April\%2005.ppt.

Hylton, K. (2005) 'Race', sport and leisure: lessons from critical race theory. Leisure Studies, 24(1), 81-98.

Hylton, K. and Totten, M. (2001). Developing ‘sport for all’? Addressing inequality in sport. In K. Hylton, P. Bramham, D. Jackson, \& M. Nesti (ed). Sports Development: Policy, Process and Practice. London: Routledge, 37-65.

Jones, B.A., Arcelus, J., Bouman, W.P. and Haycraft, E. (2016). Sport and Transgender People: A Systematic Review of the Literature Relating to Sport Participation and Competitive Sport Policies. Sports Medicine, 47(4), 701-716.

Kerfoot, D. and Knights, D. (1998). Managing masculinity in contemporary organizational life: A managerial project. Organization, 5(1), 7-26.

King, C.R. (2005). Cautionary notes on whiteness and sports studies. Sociology of Sport, 22, 397-408.

Levitas, R. (1998). The inclusive society?: Social exclusion and New Labour. Houndmills, Basingstoke, Hampshire: Macmillan.

Long, J. and Hylton, K. (2002). Shades of white: an examination of whiteness in sport. Leisure Studies [online], 21(2), 87-103.

Long, J., Robinson, P. and Spracklen, K. (2005). Promoting Racial Equality within Sports Organizations. Journal of Sport \& Social Issues [online], 29(1), 41-59. Available at: http://jss.sagepub.com/cgi/content/abstract/29/1/41.

Lusted, J. and O'Gorman, J. (2010). The impact of New Labour's modernisation agenda on the English grass-roots football workforce. Managing Leisure [online], 15(1-2), 140-154 Available at: http://dx.doi.org/10.1080/13606710903448236.

Macmillan, K. (2016). Equality and Sports Research. Glasgow: Research Scotland. 
McKay, J., Messner, M.A. and Sabo, D. (2000). Masculinities, gender relations, and sport. London: SAGE.

McNay, L. (2000). Gender and agency: reconfiguring the subject in feminist and social theory. Cambridge; Malden, Mass., Polity Press.

Meyerson, D.E. and Fletcher, J.K. (2000). A modest manifesto for shattering the glass ceiling. Boston, Harvard Business Review.

Newman, J. (2002). Theme: Gender, the Professions and Public Management: Changing Governance, Changing Equality? New Labour, Modernization and Public Services. Public Money and Management, 22(1), 7-14.

Newman, J. (2001) Modernising governance: new Labour, policy, and society London, Sage.

Rao A, Stuart R and Kelleher D (Eds) (1999). Gender at Work: Organizational Change for Equality. West Hartford: Kumarian Press.

Shaw, S. (2007). Touching the intangible? An analysis of The Equality Standard: A Framework for Sport. Equal Opportunities International, 26(5), 420-434.

Shaw, S. and Frisby, W. (2006). Can Gender Equity Be More Equitable?: Promoting an Alternative Frame for Sport Management Research, Education, and Practice. Journal of Sport Management, 20(4), 483-509.

Shaw, S. and Hoeber, L. (2003). "A Strong Man Is Direct and a Direct Woman Is a Bitch": Gendered Discourses and Their Influence on Employment Roles in Sport Organizations. Journal of Sports Management. 17(4), 347-376. [Accessed 7/13/2015].

Shaw, S. and Slack, T. (2002). 'It's been like that for Donkey's Years': The Construction of Gender Relations and the Cultures of Sports Organizations. Culture, Sport, Society, 5(1), 86-106.

Shaw, S. and Penney, D. (2003) Gender equity policies in national governing bodies: An oxymoron or a vehicle for change? European Sport Management Quarterly, 3(2), 78102.

Spittal, M. (2002). 'The New Zealand conference on database integration and linked employer- employee data’’ Social Policy Journal of New Zealand, 18, 198-202.

Sporting Equals (2012). Who's on board? Evaluating diversity in Sport Leadership. [online]. Sporting Equals. [Accessed 5/12/2016]. Available at: http://www.seleaderboard.com/PICS/Whos On board Report.pdf.

Sports Council Equality Group (2014). The Equality Standard for Sport - Achievements [online]. [Accessed 7/12/2015]. Available at: http://equalityinsport.org/equalitystandard-for-sport/achievements/.

Sports Council Equality Group (2014). The Equality Standard for Sport - Glossary of Terms [online]. [Accessed 23/06/2017]. Available at: http://equalityinsport.org/wpcontent/uploads/2014/02/Glossary-of-Terms.pdf

Sports Council Equality Group (2014). The Equality Standard Requirements-Forms.pdf [online]. [Accessed 7/12/2015]. Available at: http://www.equalityinsport.org/wpcontent/uploads/2014/02/Requirements-Forms.pdf. 
Spracklen, K., Hylton, K. and Long, J. (2006). Managing and Monitoring Equality and Diversity in UK Sport. An Evaluation of the Sporting Equals Racial Equality Standard and Its Impact on Organizational Change Journal of Sport \& Social Issues, 30(3), 289305.

The Forum for Sexual Orientation and Gender Identity Equality in Post-School Education. NUS_grid_AW_040313 - 2016_Pride_and_Prejudice_in_Education.pdf [online]. [Accessed 3/20/2016]. Available at: http://www.nus.org.uk/Global/2016_Pride_and_Prejudice_in_Education.pdf.

The National Archives The Equality Act 2010 Legislation.gov.uk. [Accessed 19/05/2016]. Available at: https://www.legislation.gov.uk/ukpga/2010/15/contents.

Thomas, N. and Smith, A. (2009). Disability, sport and society: an introduction. London: Routledge.

Thompson, N. and Thompson S. (2008). The critically reflective practitioner. Palgrave Macmillan.

Walters, G., Trenberth, L. and Tacon, R. (2010). Good governance in sport: a survey of UK national governing bodies of sport [online]. London-last update Birkbeck Institutional Research Online. [Accessed 11/4/2016]. Available at: http://eprints.bbk.ac.uk/10744/.

White, A. and Brackenridge, C. (1985). Who Rules Sport? Gender Divisions in the Power Structure of British Sports Organisations from 1960. International Review for the Sociology of Sport [online], 20(1-2), 95-107.

White, M. and Kay, J. (2006) Who Rules Sport Now?: White and Brackenridge Revisited. International Review for the Sociology of Sport, 41(3-4), 465-473.

Women's Sport and Fitness Foundation (2014). Trophy Women, NGB Leadership Audit 2014 [online]. London: Women's Sport and Fitness Foundation. [Accessed 7/13/2015]. Available at: https://www.womeninsport.org/resources/trophy-women-2014/.

Woodhouse, D. and Williams, J. (1999). Offside?: the position of women in football. [online] Reading: South Street. 68. 